Article

\title{
Supramolecular Sandwiches: Halogen-Bonded Coformers Direct [2+2] Photoreactivity in Two-Component Cocrystals
}

\author{
Jay Quentin ${ }^{1} \mathbb{D}$, Dale C. Swenson ${ }^{1}$ and Leonard R. MacGillivray ${ }^{1, * \mathbb{D}}$ \\ Department of Chemistry, University of Iowa, Iowa City, IA 52242, USA; jay-bell@uiowa.edu (J.Q.); \\ dale-swenson@uiowa.edu (D.C.S.) \\ * Correspondence: len-macgillivray@uiowa.edu
}

Academic Editor: Gianluca Ciancaleoni

Received: 18 January 2020; Accepted: 11 February 2020; Published: 18 February 2020

check for updates

\begin{abstract}
The halogen-bond (X-bond) donors 1,3- and 1,4-diiodotetrafluorobenzene (1,3-di-I-tFb and 1,4-di-I-tFb, respectively) form cocrystals with trans-1,2-bis(2-pyridyl)ethylene $\left(\mathbf{2}, \mathbf{2}^{\prime}\right.$-bpe)

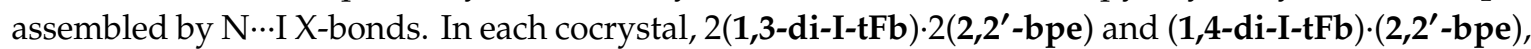

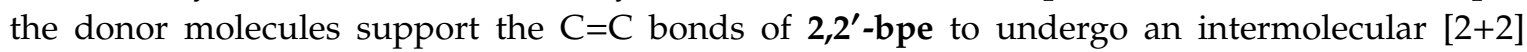
photodimerization. UV irradiation of each cocrystal resulted in stereospecific and quantitative conversion of $2,2^{\prime}$-bpe to $r c t t$-tetrakis(2-pyridyl)cyclobutane $\left(2,2^{\prime}\right.$-tpcb). In each case, the reactivity occurs via face-to-face $\pi$-stacked columns wherein nearest-neighbor pairs of $\mathbf{2}, \mathbf{2}^{\prime}$-bpe molecules lie sandwiched between $\mathrm{X}$-bond donor molecules. Nearest-neighbor $\mathrm{C}=\mathrm{C}$ bonds are stacked criss-crossed in both cocrystals. The reactivity was ascribed to the olefins undergoing pedal-like motion in the solid state. The stereochemistry of $\mathbf{2 , \mathbf { 2 } ^ { \prime }}$-tpcb is confirmed in cocrystals $2(\mathbf{1}, \mathbf{3}-\mathbf{d i}-\mathbf{I}-\mathbf{t F b}) \cdot\left(\mathbf{2}, \mathbf{2}^{\prime} \mathbf{- t p c b}\right)$ and $(1,4-d i-I-t F b) \cdot\left(2,2^{\prime}-\right.$ tpcb $)$.
\end{abstract}

Keywords: cocrystal; crystal engineering; halogen bonding; photodimerization; cyclobutane; pedal motion

\section{Introduction}

Halogen bonding (X-bonding) is a well-established [1] supramolecular synthon, as this directional, noncovalent force can reliably direct the self-assembly of molecules into supramolecular architectures [2,3]. Electrophilic regions associated with halogen $(X)$ atoms that serve as $X$-bond donors recognize complementary, nucleophilic (:Nu) functionalities (e.g., $\mathrm{N}$-atoms) on acceptor molecules such that an $X$-bond, a special class of Lewis acid-base adduct, $X \cdots \mathrm{Nu}$, results [4].

Due to the highly directional character of $\mathrm{X}$-bonds, $\mathrm{X}$-bond donor molecules with rigid geometries have attracted much interest in the field of crystal engineering. A necessary, albeit admittedly ambitious, aim is to achieve a functional level of predictive power in the design of desired geometries and/or topologies based principally on geometries of the X-bond donor and acceptor molecules [2,3]. Successes would be invaluable in the design of functional materials and would constitute a major accomplishment for the fields of crystal engineering and supramolecular chemistry.

In this context, an application of X-bonding of interest to our group is that of exploiting X-bonds as supramolecular synthons to design photoreactive solids. We have devoted efforts to investigate whether multicomponent systems can be assembled into predictable geometries based primarily on the directional character of X-bonds and molecular structures of the components. Ideally, judicious choice of coformers would enable access to solids of functional significance, such as reactivity [5-9].

Perfluorinated iodoarenes are well-established X-bond donors and are currently among the most frequently employed building blocks in the crystal engineering of X-bonded materials. In the context of 
systematic, geometry-based design, such donors are attractive owing to their planar and rigid structure as well as the well-established enhancement of X-bond donor capability by poly-fluorosubstitution [10]. We very recently described [11] that the cocrystallization of 1,2-diiodotetrafluorobenzene (1,2-di-I-tFb) with trans-1,2-bis( $n$-pyridyl)ethylene $\left(n, n^{\prime}\right.$-bpe, where: $\left.n=n^{\prime}=2,3,4\right)$ affords cocrystals sustained by N...I X-bonds that make up one-dimensional (1D) and two-dimensional (2D) assemblies. For 2,2'-bpe, the components generated a discrete aggregate packed as a photostable 1D assembly.

Among the structural isomers of diiodotetrafluorobenzene, the most ubiquitous X-bond donor is 1,4-di-I-tFb, with a far less common donor being 1,3-di-I-tFb (Scheme 1). A survey of the Cambridge Structural Database (CSD) [12] revealed 146 structures that involve 1,4-di-I-tFb as an X-bond donor,

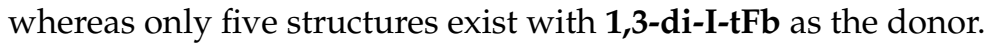

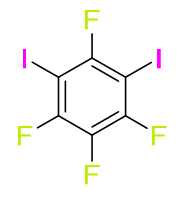

1,3-di-I-tFb

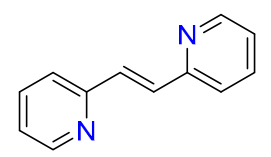

2,2'-bpe<smiles>Fc1c(F)c(I)c(F)c(I)c1F</smiles>

1,4-di-I-tFb

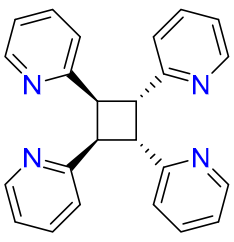

2,2'-tpcb

Scheme 1. Components for cocrystals.

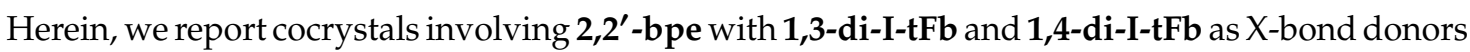
(Scheme 1). The components of each cocrystal, 2(1,3-di-I-tFb)·2(2,2'-bpe) and (1,4-di-I-tFb)·(2,2' -bpe), assembled into 1D chains mediated by N...I X-bonds. Adjacent chains interacted via face-to-face $\pi$-stacking interactions such that two molecules of $2, \mathbf{2}^{\prime}$-bpe lay sandwiched between $X$-bond donors. We show the arrangements that enabled each sandwiched, nearest-neighbor pair of $\mathbf{2}, \mathbf{2}^{\prime}$-bpe to undergo an intermolecular [2+2] photodimerization to furnish rctt-tetrakis(2-pyridyl)cyclobutane $\left(\mathbf{2}, \mathbf{2}^{\prime}\right.$-tpcb) quantitatively and stereospecifically (Scheme 2). The solid-state reactivity occurred despite the major fraction of nearest-neighbor $\mathrm{C}=\mathrm{C}$ bonds of $\mathbf{2 , 2} \mathbf{2}^{\prime}$-bpe laying stacked criss-crossed in the solids. We ascribed the reactivity to the $\mathrm{C}=\mathrm{C}$ bonds undergoing solid-state pedal-like motion [13-22]. The photoproduct was confirmed in the X-bonded cocrystals $2(\mathbf{1}, \mathbf{3}-\mathrm{di}-\mathrm{I}-\mathrm{tFb}) \cdot\left(\mathbf{2}, \mathbf{2}^{\prime}\right.$-tpcb) and $(\mathbf{1}, \mathbf{4}-\mathrm{di}-\mathrm{I}-\mathbf{t F b}) \cdot\left(\mathbf{2}, \mathbf{2}^{\prime}-\mathbf{t p c b}\right)$.

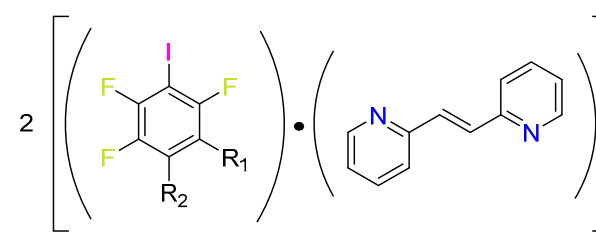

(di-I-tFb).(2,2'-bpe)

$$
R_{1}=I, R_{2}=F: 1,3-d i-I-t F b
$$$$
R_{1}=F, R_{2}=I: 1,4-d i-I-t F b
$$

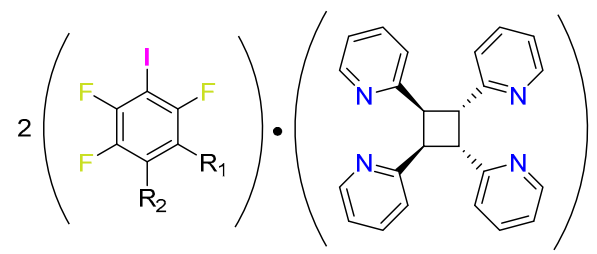

2(di-I-tFb)-(2,2'-tpcb) single diastereomer

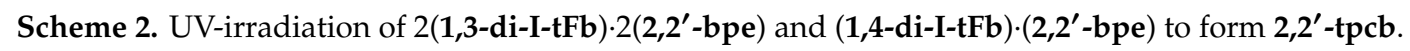




\section{Results and Discussion}

\subsection{X-ray Structure of 2(1,3-di-I-tFb) 2(2,2'-bpe)}

The components of 2(1,3-di-I-tFb)-2(2,2'-bpe) crystallized in the orthorhombic, noncentrosymmetric space group $P n a 2_{1}$ (Table 1 ). The asymmetric unit consists of two molecules of 1,3-di-I-tFb and two molecules of 2,2' -bpe that assemble by a combination of N $\cdots$ I X-bonds $(d(I 1 \cdots N 1)$ $=2.96(2) \AA ; d(\mathrm{I} 2 \cdots \mathrm{N} 2)=3.00(1) \AA ; d(\mathrm{I} 3 \cdots \mathrm{N} 3)=2.99(1) \AA ; d(\mathrm{I} 4 \cdots \mathrm{N} 4)=3.04(1) \AA)$ (Table 2), as well as edge-to-edge C-H $\cdots$ I and C-H...F contacts (Figure $1 \mathrm{a}$, Table 3 ). The pyridyl rings of one molecule of $\mathbf{2}, \mathbf{2}^{\prime}$-bpe $(\mathrm{N} 1 / \mathrm{N} 2)$ lie perfectly coplanar (twist angle $=0.00^{\circ}$ ), whereas the pyridyl rings of the other $(\mathrm{N} 3 / \mathrm{N} 4)$ deviate from coplanarity (twist angle $\sim 5.35^{\circ}$ ). Both molecules of $\mathbf{2 , 2 ^ { \prime }}$-bpe adopt an

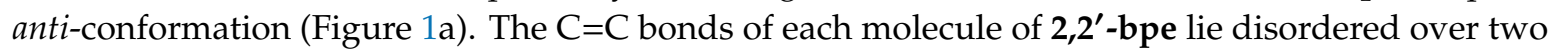
sites (occupancies: 72/28 [N1/N2]; 72/28 [N3/N4]). The major fraction (72\%) of nearest-neighbor C=C bonds lie criss-crossed [13]. 
Table 1. Crystallographic data and structure refinement statistics *.

\begin{tabular}{|c|c|c|c|c|}
\hline Cocrystal & $2(1,3-d i-I-t F b) \cdot 2\left(2,2^{\prime}-b p e\right)$ & $2(1,3-\mathrm{di}-\mathrm{I}-\mathrm{tFb}) \cdot\left(2,2^{\prime}-\mathrm{tpcb}\right)$ & $(1,4-\mathrm{di}-\mathrm{I}-\mathrm{tFb}) \cdot\left(2,2^{\prime}-\mathrm{bpe}\right)$ & $(1,4-\mathrm{di}-\mathrm{I}-\mathrm{tFb}) \cdot\left(2,2^{\prime}\right.$-tpcb) \\
\hline CCDC deposition number & 1940759 & 1967637 & 1940762 & 1967634 \\
\hline Empirical formula & $\mathrm{C}_{18} \mathrm{H}_{10} \mathrm{~F}_{4} \mathrm{I}_{2} \mathrm{~N}_{2}$ & $\mathrm{C}_{36} \mathrm{H}_{20} \mathrm{~F}_{8} \mathrm{I}_{4} \mathrm{~N}_{4}$ & $\mathrm{C}_{18} \mathrm{H}_{10} \mathrm{~F}_{4} \mathrm{I}_{2} \mathrm{~N}_{2}$ & $\mathrm{C}_{30} \mathrm{H}_{20} \mathrm{~F}_{4} \mathrm{I}_{2} \mathrm{~N}_{4}$ \\
\hline Formula weight $/ \mathrm{g} \cdot \mathrm{mol}^{-1}$ & 584.08 & 1168.16 & 584.08 & 766.3 \\
\hline Temperature/K & 296.15 & 150.15 & 296.15 & 296.15 \\
\hline Crystal system & orthorhombic & monoclinic & tetragonal & monoclinic \\
\hline Space group & Pna $2_{1}$ & $P 2_{1} / \mathrm{c}$ & $I 4_{1} \mathrm{~cd}$ & $\mathrm{C} 2 / \mathrm{c}$ \\
\hline$a / \AA$ & $21.975(2)$ & $9.3925(9)$ & 14.1404(14) & 25.422(3) \\
\hline$b / \AA ̊$ & 19.2247(19) & $18.8849(19)$ & $14.1404(14)$ & $5.4525(5)$ \\
\hline$c / \AA ̊$ & $9.0190(9)$ & $20.596(2)$ & $38.138(4)$ & 21.183(2) \\
\hline$\alpha /^{\circ}$ & 90 & 90 & 90 & 90 \\
\hline$\beta /^{\circ}$ & 90 & $90.337(5)$ & 90 & $112.099(5)$ \\
\hline$\gamma /{ }^{\circ}$ & 90 & 90 & 90 & 90 \\
\hline Volume $/ \AA^{3}$ & $3810.2(6)$ & $3653.2(6)$ & 7625.7(17) & $2720.5(5)$ \\
\hline Z & 8 & 4 & 16 & 4 \\
\hline$\rho_{\text {cald }} / \mathrm{g} \cdot \mathrm{cm}^{-3}$ & 2.036 & 2.124 & 2.035 & 1.871 \\
\hline$\mu / \mathrm{mm}^{-1}$ & 3.342 & 3.486 & 3.34 & 2.367 \\
\hline$F(000)$ & 2192 & 2192 & 4384 & 1480 \\
\hline Crystal size $/ \mathrm{mm}^{3}$ & $0.32 \times 0.23 \times 0.22$ & $0.205 \times 0.145 \times 0.03$ & $0.23 \times 0.19 \times 0.045$ & $0.16 \times 0.16 \times 0.05$ \\
\hline Radiation & $\operatorname{MoK} \alpha(\lambda=0.71073)$ & $\operatorname{MoK} \alpha(\lambda=0.71073)$ & $\operatorname{MoK} \alpha(\lambda=0.71073)$ & $\operatorname{MoK} \alpha(\lambda=0.71073)$ \\
\hline $2 \Theta$ range for data collection $/^{\circ}$ & 3.706 to 53.308 & 4.844 to 52.798 & 5.762 to 53.438 & 6.326 to 53.426 \\
\hline Index ranges & $-27 \leq \mathrm{h} \leq 27,-24 \leq \mathrm{k} \leq 23,-11 \leq 1 \leq 11$ & $-11 \leq \mathrm{h} \leq 11,-23 \leq \mathrm{k} \leq 23,-25 \leq 1 \leq 25$ & $-17 \leq \mathrm{h} \leq 17,-17 \leq \mathrm{k} \leq 17,-48 \leq 1 \leq 41$ & $-32 \leq \mathrm{h} \leq 32,-6 \leq \mathrm{k} \leq 6,-26 \leq 1 \leq 21$ \\
\hline Reflections collected & 24085 & 41568 & 21996 & 7854 \\
\hline Independent reflections & $7967\left[R_{\text {int }}=0.0302, R_{\text {sigma }}=0.0287\right]$ & $7413\left[R_{\mathrm{int}}=0.0373, R_{\text {sigma }}=0.0299\right]$ & $3771\left[R_{\mathrm{int}}=0.0374, R_{\text {sigma }}=0.0225\right]$ & $2870\left[R_{\text {int }}=0.0338, R_{\text {sigma }}=0.0413\right]$ \\
\hline Data/restraints/parameters & $7967 / 1 / 482$ & $7413 / 4 / 498$ & $3771 / 1 / 242$ & $2870 / 1 / 196$ \\
\hline Goodness-of-fit on $F^{2}$ & 1.091 & 1.153 & 1.062 & 1.077 \\
\hline Final $R$ indices $[I \geq 2 \sigma(I)]$ & $R_{1}=0.0537$ & $R_{1}=0.0463$ & $R_{1}=0.0260$ & $R_{1}=0.0352$ \\
\hline & $w R_{2}=0.1355$ & $w R_{2}=0.0864$ & $w R_{2}=0.0552$ & $w R_{2}=0.0745$ \\
\hline$R$ indices (all data) & $R_{1}=0.0685$ & $R_{1}=0.0613$ & $R_{1}=0.0394$ & $R_{1}=0.0641$ \\
\hline & $w R_{2}=0.1522$ & $w R_{2}=0.0926$ & $w R_{2}=0.0603$ & $w R_{2}=0.0838$ \\
\hline Largest diff. peak/hole $/ \mathrm{e} \cdot \AA^{-3}$ & $3.50 /-1.09$ & $3.41 /-3.00$ & $0.24 /-0.34$ & $0.441 /-0.676$ \\
\hline Flack parameter & $0.284(14)$ & - & $0.254(13)$ & - \\
\hline
\end{tabular}


The components formed two crystallographically-unique 1D chains wherein each molecule of 1,3-di-I-tFb bridges two molecules of 2,2' -b pe via the N...IX-bonds (Figure $1 \mathrm{~b}, \mathrm{c}$ ). Assembly properties of the X-bonded cocrystals 2(1,3-di-I-tFb)·2(2,2' -bpe), 2(1,3-di-I-tFb)·(2,2'-tpcb), (1,4-di-I-tFb)·(2,2' -bpe), and $(\mathbf{1}, \mathbf{4}-\mathbf{d i}-\mathbf{I}-\mathbf{t F b}) \cdot\left(\mathbf{2}, \mathbf{2}^{\prime}\right.$-tpcb) are addressed below (Table 3). The chains interact by way of offset, face-to-face $\pi$-stacks involving 1,3-di-I-tFb of one chain and one pyridyl (pyr) ring of 2,2'-bpe of the other chain $\left(d\left(\operatorname{pyr}_{[\mathrm{N} 2]} \cdots \mathbf{1 , 3 - d i - I - t F b}{ }_{[\mathrm{I} 3 / \mathrm{I} 4]} \sim 4.48 \AA ; d\left(\operatorname{pyr}_{[\mathrm{N} 4]} \cdots \mathbf{1 , 3}\right.\right.\right.$-di-I-tFb $\left.{ }_{[\mathrm{I} 1 / \mathrm{I} 2]} \sim 4.55 \AA\right)$. Across the $\pi$-stacked chains, two molecules of $2, \mathbf{2}^{\prime}$-bpe lie sandwiched between two unique molecules of 1,3-di-I-tFb in an ABB' $^{\prime} \mathrm{A}^{\prime}$ motif (Figure 1e, Table 3). As a consequence of this arrangement, nearest-neighbor molecules of $\mathbf{2}, \mathbf{2}^{\prime}$-bpe stack parallel with $\mathrm{C}=\mathrm{C}$ bonds separated on the order of $3.64 \AA$.

Table 2. X-bond metrics for cocrystals.

\begin{tabular}{|c|c|c|c|c|c|}
\hline Cocrystal & X-Bond & $d(\mathrm{~N} \cdots \mathrm{I}) / \AA ̊ \AA$ & $\Theta(C-I \cdots N) /^{\circ}$ & X-Bond Type & Prs * \\
\hline \multirow[t]{4}{*}{ 2(1,3-di-I-tFb) $\cdot\left(\mathbf{2}, \mathbf{2}^{\prime}\right.$-bpe $)$} & $\mathrm{I} 1 \cdots \mathrm{N} 1$ & $2.96(2)$ & 172.64 & I & 16 \\
\hline & $\mathrm{I} 2 \cdots \mathrm{N} 2$ & $3.00(1)$ & 174.16 & $\mathrm{I}$ & 15 \\
\hline & $\mathrm{I} 3 \cdots \mathrm{N} 3$ & 2.99(1) & 172.24 & I & 15 \\
\hline & $\mathrm{I} 4 \cdots \mathrm{N} 4$ & $3.04(1)$ & 174.42 & I & 14 \\
\hline \multirow{4}{*}{$2(1,3-\mathrm{di}-\mathrm{I}-\mathrm{tFb}) \cdot\left(2,2^{\prime}-\mathrm{tpcb}\right)$} & $\mathrm{I} 1 \cdots \mathrm{N} 1$ & $2.949(6)$ & 174.39 & I & 16 \\
\hline & $\mathrm{I} 2 \cdots \mathrm{N} 4$ & $3.009(6)$ & 167.06 & I & 15 \\
\hline & $\mathrm{I} 3 \cdots \mathrm{N} 3$ & $2.947(6)$ & 177.44 & I & 17 \\
\hline & $\mathrm{I} 4 \cdots \mathrm{N} 2$ & $3.131(6)$ & 169.48 & I & 11 \\
\hline \multirow[t]{2}{*}{$(1,4-d i-I-t F b) \cdot\left(2,2^{\prime}-\right.$ bpe $)$} & $\mathrm{I} 1 \cdots \mathrm{N} 1$ & $2.967(8)$ & 177.09 & I & 16 \\
\hline & $\mathrm{I} 2 \cdots \mathrm{N} 2$ & $2.982(8)$ & 177.16 & I & 16 \\
\hline \multirow[t]{2}{*}{$(1,4-d i-I-t F b) \cdot\left(2,2^{\prime}-t p c b\right)$} & $\mathrm{I} 1 \cdots \mathrm{N} 1 \mathrm{~A}$ & $3.064(4)$ & 174.36 & I & 13 \\
\hline & $\mathrm{I} 1 \cdots \mathrm{N} 1 \mathrm{~B}$ & $2.942(4)$ & 171.42 & I & 17 \\
\hline
\end{tabular}

Although the $\mathrm{C}=\mathrm{C}$ bonds of $\mathbf{2}, \mathbf{2}^{\prime}$-bpe adopt a criss-crossed geometry, the alkene is photoactive. UV irradiation of a microcrystalline sample of $2(\mathbf{1}, \mathbf{3}-\mathbf{d i}-\mathbf{I}-\mathbf{t F b}) \cdot 2\left(\mathbf{2}, \mathbf{2}^{\prime} \mathbf{- b} \mathbf{p e}\right)$ for a period of $20 \mathrm{~h}$ resulted in stereospecific and quantitative conversion of $\mathbf{2 , 2} \mathbf{2}^{\prime}-\mathbf{b} \mathbf{p e}$ to $\mathbf{2 , 2}-\mathbf{t} \mathbf{p c b}$. The formation of the photoproduct was evidenced by the complete disappearance of the olefinic resonance $(7.70 \mathrm{ppm})$ and emergence of a single cyclobutane resonance $(4.93 \mathrm{ppm})[23,24]$. We note that, as a single component, $\mathbf{2}, \mathbf{2}^{\prime}$-bpe has been reported to be photostable [24].

Table 3. Structural features of cocrystals.

\begin{tabular}{|c|c|c|c|}
\hline Cocrystal & Primary Assembly & Secondary Assembly & Photoreactivity \\
\hline $2(1,3-\mathrm{di}-\mathrm{I}-\mathrm{tFb}) \cdot 2\left(\mathbf{2 , 2 ^ { \prime } - \mathrm { bpe } )}\right.$ & $\begin{array}{l}\text { two unique, infinite 1D chains based } \\
\text { on N...I }\end{array}$ & $\begin{array}{l}\text { face-to-face } \mathrm{ABB}^{\prime} \mathrm{A}^{\prime} \\
\pi \text {-stacked sandwiches }\end{array}$ & active \\
\hline $2(1,3-\mathrm{di}-\mathrm{I}-\mathrm{tFb}) \cdot\left(\mathbf{2}, \mathbf{2}^{\prime}-\mathrm{tpcb}\right)$ & $\begin{array}{l}\text { infinite 1D chain based on N } \cdots I \text { and } \\
\text { face-to-face } \pi \text {-stacks }\end{array}$ & - & - \\
\hline$(1,4-d i-I-t F b) \cdot\left(2,2^{\prime}-b p e\right)$ & 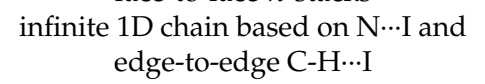 & $\begin{array}{l}\text { face-to-face ABBA } \\
\pi \text {-stacked sandwiches }\end{array}$ & active \\
\hline$(1,4-\mathrm{di}-\mathrm{I}-\mathrm{tFb}) \cdot\left(2,2^{\prime}-\mathrm{tpcb}\right)$ & infinite zig-zag chains based on N...I & $\begin{array}{l}\text { herringbone pattern } \\
\text { based on } \mathrm{C}-\mathrm{H} \cdots \mathrm{N}\end{array}$ & - \\
\hline
\end{tabular}




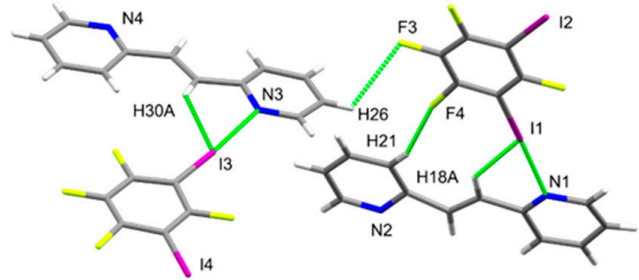

(a)

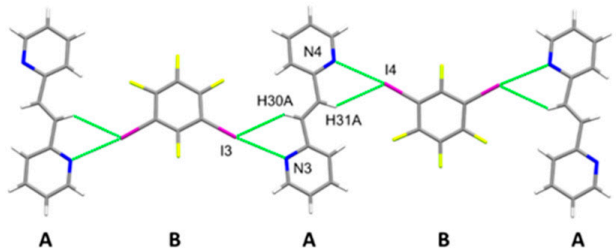

(c)

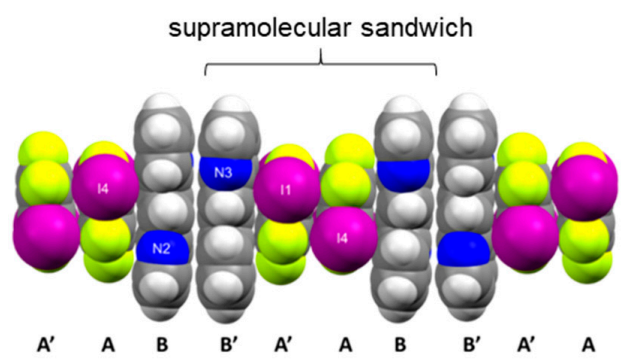

(e)

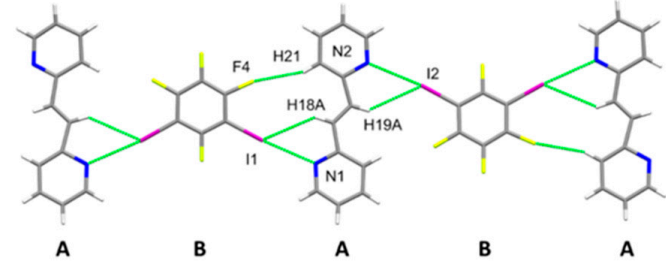

(b)

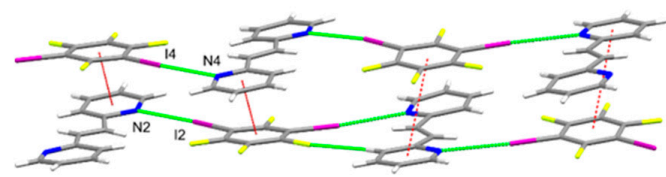

(d)

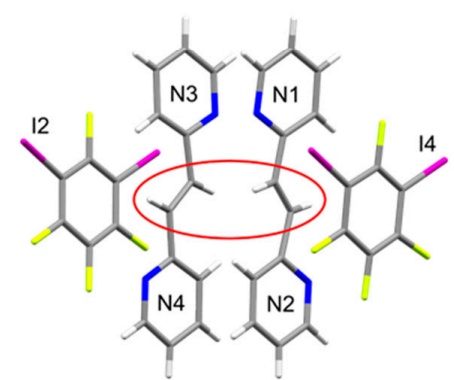

(f)

Figure 1. Perspectives of 2(1,3-di-I-tFb) $2\left(2,2^{\prime}\right.$-bpe): (a) asymmetric unit (olefin disorder omitted for clarity); (b) 1D chain based on N1/N2 illustrating ABAB repeat unit; (c) 1D chain based on N3/N4 illustrating $\mathrm{ABAB}$ repeat unit; (d) offset, face-to-face $\pi$-stacks (highlighted in red) between chains; (e) face-to-face $\pi$-stacked sandwiches (space-filling) illustrating ABB' $^{\prime} \mathrm{A}^{\prime}$ repeat unit; and (f) $\pi$-stacked sandwiches highlighting criss-crossed $\mathrm{C}=\mathrm{C}$ bonds (olefin disorder omitted for clarity).

\subsection{X-ray Structure of $2(\mathbf{1}, 3-d i-I-t \boldsymbol{F b}) \cdot\left(2,2^{\prime}-t \boldsymbol{p c b}\right)$}

The photoproduct $\mathbf{2}, \mathbf{2}^{\mathbf{\prime}}$-tpcb interacts with $\mathbf{1 , 3}$-di-I-tFb as a tetratopic $[25,26]$ X-bond acceptor. The components of $2(\mathbf{1}, \mathbf{3}-\mathbf{d i}-\mathbf{I}-\mathbf{t F b}) \cdot\left(\mathbf{2}, \mathbf{2}^{\prime}\right.$-tpcb) crystallize in the monoclinic space group $P 2_{1} / c$ (Table 1 ). The asymmetric unit consists of two unique molecules of $\mathbf{1}, \mathbf{3}-\mathrm{di}-\mathrm{I}-\mathbf{t F b}$ and one molecule of $\mathbf{2}, \mathbf{2}^{\prime} \mathbf{- t p c b}$. The cyclobutane ring lies disordered over two sites (occupancies: 84/16 at $T=150.15 \mathrm{~K}$ ). The molecules of 1,3-di-I-tFb interact with each another via face-to-face $\pi$-stacks $(d \sim 3.77 \AA$, Figure $2 \mathrm{a})$. The cyclobutane 2,2' -tpcb interacts with one molecule of 1,3-di-I-tFb [I3/I4] via two face-to-face $\pi \cdots$ F forces involving two of the pyridyl (pyr) rings of $2,2^{\prime}-\operatorname{tpcb}\left(d\left(\operatorname{pyrr}_{[\mathrm{N} 11} \cdots \mathrm{F} 5\right) \sim 3.71 \AA\right.$; $d\left(\operatorname{pyr}_{[\mathrm{N} 4]^{\cdots}} \cdots \mathrm{F} 6\right) \sim 3.42 \AA$, Figure 2a). As a consequence of the assembly process, the components form $1 \mathrm{D}$ chains via a combination of $\mathrm{N} \cdots \mathrm{I}$ X-bonds $(d(\mathrm{I} 1 \cdots \mathrm{N} 1)=2.949(6) \AA ; d(\mathrm{I} 2 \cdots \mathrm{N} 4)=3.009(6) \AA ; d(\mathrm{I} 3 \cdots \mathrm{N} 3)=2.947(6) \AA ; d(\mathrm{I} 4 \cdots \mathrm{N} 2)=3.131(6) \AA)$ (Table 2) and face-to-face $\pi$-stacks between molecules of $\mathbf{1 , 3}-\mathbf{d i - I t F b}$ (Figure 2a,b, Table 3). 


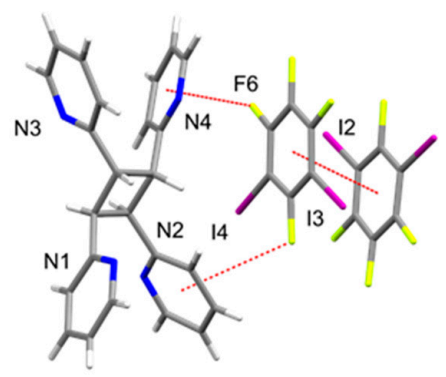

(a)

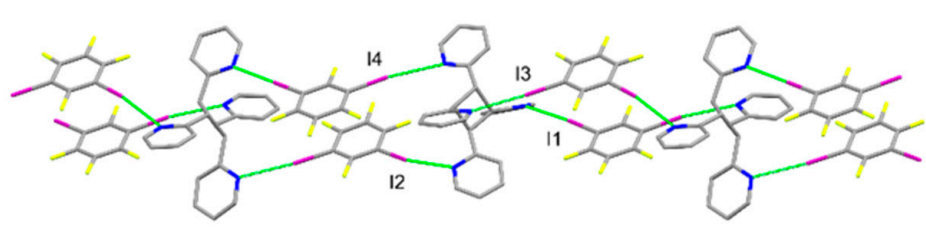

(b)

Figure 2. Perspectives of 2(1,3-di-I-tFb) $\cdot\left(\mathbf{2}, \mathbf{2}^{\prime}\right.$-tpcb): (a) asymmetric unit highlighting $\pi \cdots \pi$ and $\pi \cdots \mathrm{F}$ forces (cyclobutane disorder omitted for clarity) and (b) 1D chains (H atoms omitted for clarity).

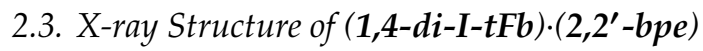

The components of (1, $\mathbf{4}-\mathbf{d i}-\mathbf{I}-\mathbf{t F b}) \cdot\left(\mathbf{2}, \mathbf{2}^{\prime}\right.$-bpe $)$ crystallize in the noncentrosymmetric tetragonal space group $I 4_{1} c d$ (Table 1). The asymmetric unit consists of one molecule of $\mathbf{1}, \mathbf{4}$-di-I-tFb and one molecule

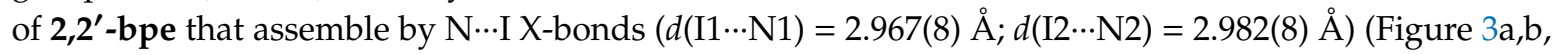
Table 2). The pyridyl rings of $\mathbf{2}, \mathbf{2}^{\prime}$-bpe lie approximately coplanar (twist angle $\sim 4.83^{\circ}$ ). The alkene

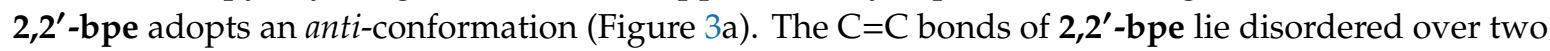
sites (occupancies: 66/34). The components form infinite 1D chains along the crystallographic $b c$-plane,

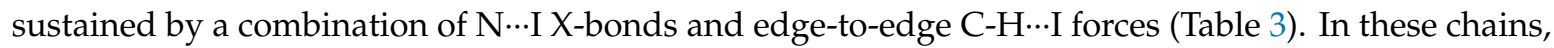

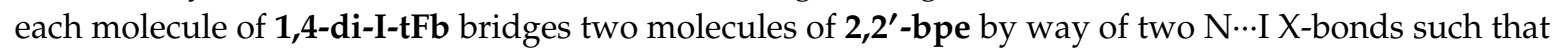
the chains repeat in an ABAB pattern (Figure 3b, Table 3). Adjacent chains interact by way of offset,

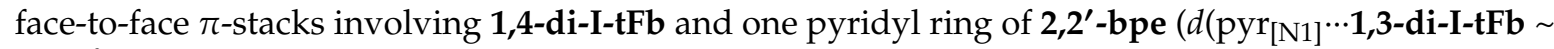
$4.67 \AA$ ) (Figure 3c).

Similar to $2\left(\mathbf{1}, \mathbf{3}\right.$-di-I-tFb) $2\left(\mathbf{2}, \mathbf{2}^{\prime}\right.$-bpe $)$, across the $\pi$-stacked chains, two molecules of $\mathbf{2 , 2} \mathbf{2}^{\prime}$-bpe lie sandwiched between two molecules of $\mathbf{1 , 3 - d i - I - t F b}$ in an ABBA motif (Figure 3d, Table 3). As a consequence of this arrangement, nearest-neighbor molecules of $2,2^{\prime}$-bpe stack parallel with $C=C$ bonds separated on the order of $3.72 \AA$, with the major sites (occupancies: $66 \%$ ) of nearest-neighbor $\mathrm{C}=\mathrm{C}$ bonds being criss-crossed [13-22]. Despite the crossed geometry, however, $\mathbf{2}, \mathbf{2}^{\prime} \mathbf{- b} \mathbf{b e}$ is photoactive. UV irradiation of a microcrystalline sample of $(\mathbf{1}, \mathbf{4}-\mathbf{d i}-\mathbf{I}-\mathbf{t F b}) \cdot\left(\mathbf{2}, \mathbf{2}^{\prime}\right.$-bpe) for a period of $20 \mathrm{~h}$ resulted in stereospecific and quantitative conversion of $\mathbf{2}, \mathbf{2}^{\prime}$-bpe to $\mathbf{2}, \mathbf{2}^{\prime}$-tpcb. Formation of the photoproduct was evidenced by complete disappearance of the olefinic resonance $(7.70 \mathrm{ppm})$ and emergence of a single cyclobutane resonance (4.93 ppm) [23,24]. 


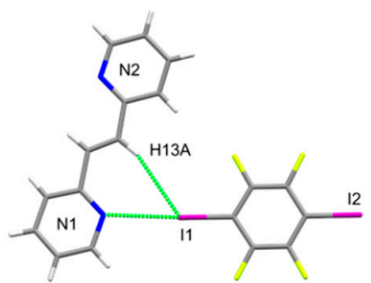

(a)

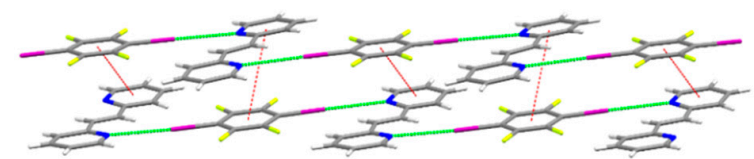

(c)

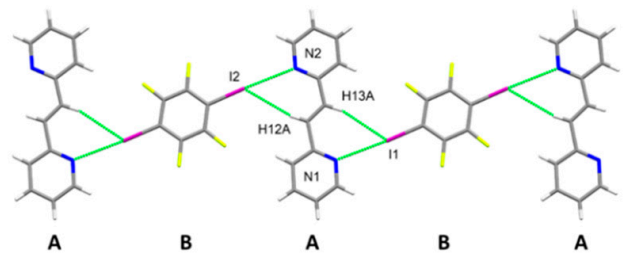

(b)

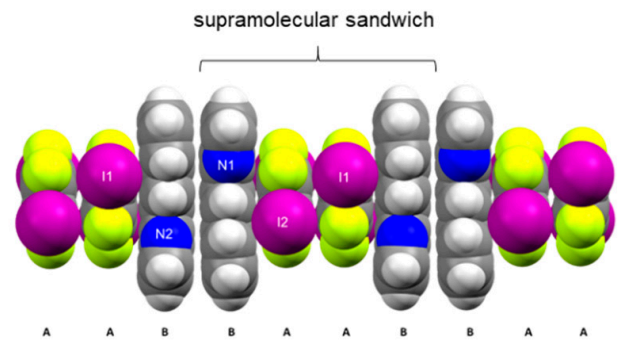

(d)

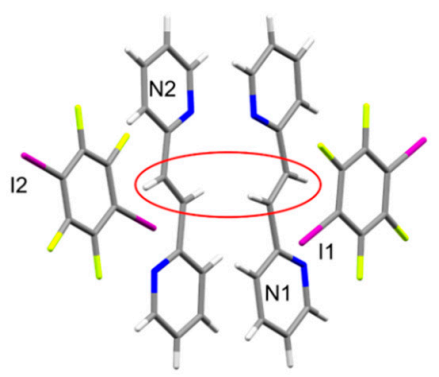

(e)

Figure 3. Perspectives of $(\mathbf{1}, \mathbf{4}-\mathbf{d i}-\mathrm{I}-\mathbf{t F b}) \cdot\left(\mathbf{2}, \mathbf{2}^{\prime}\right.$-bpe): (a) asymmetric unit; (b) 1D chain along crystallographic $b c$-plane illustrating the $\mathrm{ABAB}$ repeat unit; (c) offset, face-to-face $\pi$-stacks (highlighted in red) between chains; (d) face-to-face $\pi$-stacked sandwiches (space-filling) illustrating the ABBA repeat unit; and (e) $\pi$-stacked sandwiches highlighting criss-crossed $\mathrm{C}=\mathrm{C}$ bonds (olefin disorder omitted for clarity).

\subsection{X-ray Structure of $(1,4-d i-I-t F b) \cdot\left(2,2^{\prime}-t p c b\right)$}

The components of (1,4-di-I-tFb) $\cdot\left(\mathbf{2}, \mathbf{2}^{\prime}\right.$-tpcb) crystallize in the monoclinic space group C2/c (Table 1$)$. The asymmetric unit consists of one-half molecule of $\mathbf{1}, \mathbf{4}-\mathbf{d i}-\mathbf{I}-\mathbf{t} \mathbf{F b}$, which lies on a crystallographic center of inversion, and one-half molecule of $\mathbf{2 , 2} \mathbf{2}^{\prime}$-tpcb which lies on a two-fold axis and is disordered (occupancies: 50/50) by symmetry (Figure 4a). The components of (1,4-di-I-tFb) $\cdot\left(\mathbf{2}, \mathbf{2}^{\prime}\right.$-tpcb) assemble primarily via $\mathrm{N} \cdots \mathrm{I}$ X-bonds $(d(\mathrm{I} 1 \cdots \mathrm{N} 1 \mathrm{~A})=3.064(4) \AA ;$ zig-zag chains $\left(\lambda \sim 2.6 \mathrm{~nm}, \Theta \sim 81.6^{\circ}\right)$ (Figure $4 \mathrm{~b}$, Table 3 ). Adjacent chains interact via $\mathrm{C}-\mathrm{H} \cdots \mathrm{N}$ contacts between pyridyl rings $(d(\mathrm{C} 7-\mathrm{H} 7 \cdots \mathrm{N} 2)=3.449(8) \AA)$ to generate a herringbone pattern (Figure 4c, Table 3$)$. Adjacent molecules of $\mathbf{2 , 2}$ '-tpcb also interact via edge-to-face C-H $\cdots \pi$ forces $(d(\mathrm{C} 14-\mathrm{H} 14 \cdots$ pyr $[\mathrm{N} 1]) \sim$ $4.15 \AA)$ and offset, face-to-face $\pi \cdots \pi$ stacks $\left(d\left(\operatorname{pyrr}_{[\mathrm{N} 2]} \cdots \operatorname{pyr}_{[\mathrm{N} 2]}\right) \sim 4.51 \AA\right)$ to generate infinite 1D chains along the crystallographic $c$-axis (Figure $4 d$ ). 


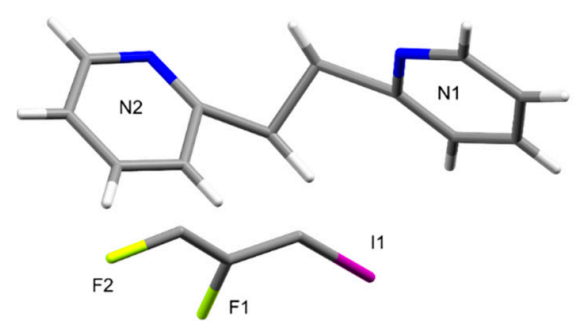

(a)

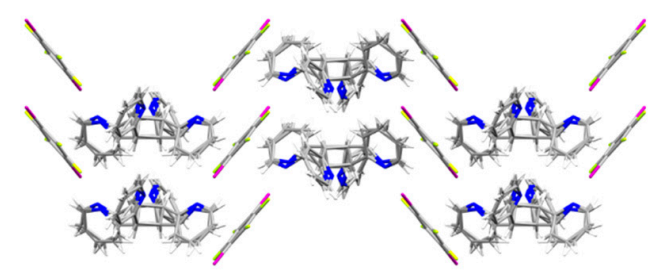

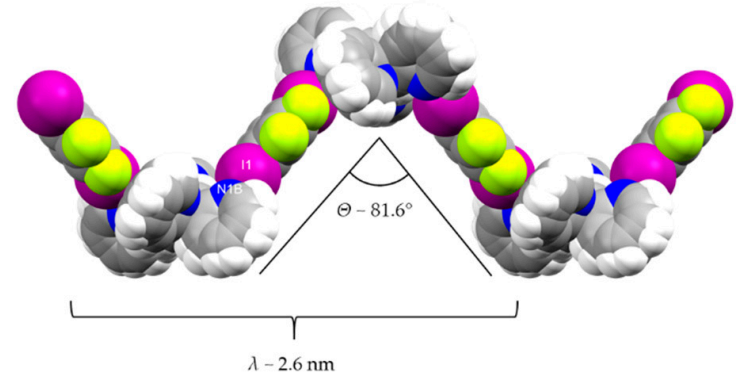

(b)

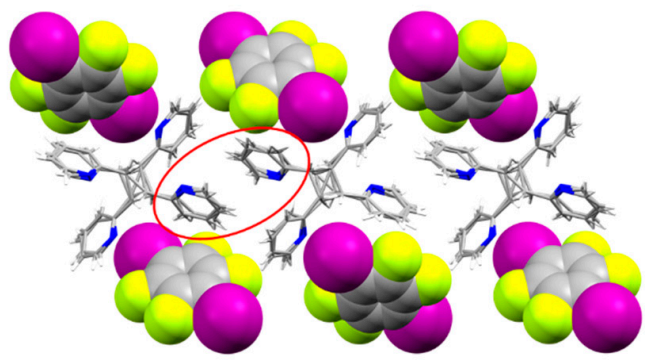

(d)

Figure 4. Perspectives of (1,4-di-I-tFb) $\left(\mathbf{2}, \mathbf{2}^{\prime}\right.$-tpcb): (a) asymmetric unit (cyclobutane disorder omitted for clarity); (b) infinite zig-zag chains (space-filling, view along c); (c) herringbone pattern resulting from interactions between zig-zag chains; and (d) $1 \mathrm{D}$ chains of $\mathbf{2 , 2}$ '-tpcb generated along the crystallographic $c$-axis, highlighting offset, face-to-face $\pi \cdots \pi$ forces.

\subsection{Photoreactivity}

We very recently invoked pedal-like motion to account for the stereospecific and quantitative [2+2] photodimerization of $3,3^{\prime}$-bpe to form $r c t t-3,3^{\prime}-$ tpcb in the hydrogen-bonded cocrystal (catechol) $\cdot\left(3,3^{\prime}\right.$-bpe) [10]. The reactivity occurred between criss-crossed $\mathrm{C}=\mathrm{C}$ bonds. Pedal motion can also be used to explain the photodimerizations of cocrystals $2(\mathbf{1}, \mathbf{3}-\mathbf{d i}-\mathbf{I}-\mathbf{t F b}) \cdot \mathbf{2}\left(\mathbf{2}, \mathbf{2}^{\prime}\right.$-bpe) and (1,4-di-I-tFb).(2,2'-bpe) to form $r c t t-2,2^{\prime}-$ tpcb. The $\mathrm{C}=\mathrm{C}$ bonds of the two cocrystals also exhibited a criss-crossed geometry that, in contrast to (catechol). $\left(3,3^{\prime}\right.$-bpe), also lie disordered. A disordered geometry is typically associated with pedal motion that supports reactivity [11,13-22].

\section{Materials and Methods}

\subsection{General Experimental}

All reagents and solvents (synthesis grade) were purchased from commercial sources and used as received unless otherwise stated. 1,3-diiodotetrafluorobenzene (1,3-di-I-tFb) was purchased from Apollo Scientific; 1,4-diiodotetrafluorobenzene (1,4-di-I-tFb) was purchased from Aldrich; trans-1,2-bis(2-pyridyl)ethylene (2,2'-bpe) was purchased from TCI America; and chloroform $\left(\mathrm{CHCl}_{3}\right.$; certified ACS grade, $\geq 99.8 \%$, approximately $0.75 \% \mathrm{EtOH}$ as preservative) was purchased from Fisher Chemical. All cocrystal syntheses were conducted in screw-cap glass scintillation vials. For cocrystal syntheses, "thermal dissolution" refers to the process of combining both solid cocrystal components in a vial, adding solvent portion-wise while maintaining a saturated mixture at room temperature (rt), and tightly capping the vial and heating the mixture on a hot-plate until all solids dissolve to afford a homogeneous solution with the minimum necessary volume of solvent. Compositions of all single crystals were shown to be representative of the bulk material by matching experimental powder X-ray diffraction (pXRD) patterns with those simulated from single-crystal X-ray diffraction (scXRD) data. Yields refer to isolated yields of analytically-pure compounds unless otherwise stated. Melting points $(\mathrm{mp})$ were recorded on samples in open capillary tubes using a manual MEL-TEMP apparatus (Electrothermal Corporation, Staffordshire, UK) and were uncorrected. Photoreactions were conducted 
in either a NuLink $36 \mathrm{~W}$ UV lamp apparatus $(\lambda=400 \mathrm{~nm})$ or an ACE photocabinet equipped with an ACE quartz, $450 \mathrm{~W}$, broadband, medium pressure, Hg-vapor lamp. Photoreactions were conducted by: (1) grinding single crystals of the cocrystal to a fine powder with an agate mortar and pestle; (2) smearing the powder between two Pyrex plates; and (3) irradiating the powder in $10 \mathrm{~h}$ intervals, taking care to ensure uniform irradiation.

\subsection{Synthetic Procedures}

2(1,3-di-I-tFb).2(2,2'-bpe). Note: 2(1,3-di-I-tFb).2(2,2'-bpe) is photosensitive. Cocrystals of 2(1,3-di-I-tFb) 2(2, $\mathbf{2}^{\prime}$-bpe) were obtained by thermal dissolution of $\mathbf{2 , 2} \mathbf{2}^{\prime}$-bpe $(85.3 \mathrm{mg}, 0.459 \mathrm{mmol})$ and 1,3-di-I-tFb (182.4 mg, $0.440 \mathrm{mmol}, 0.96$ equiv) in $\mathrm{CHCl}_{3}(2.0 \mathrm{~mL})$. Upon cooling to rt, single crystals of 2(1,3-di-I-tFb) 2(2,2' -bpe) — colorless blocks, suitable for scXRD—formed within $6 \mathrm{~d}$. Analytical data: mp 90-91 ${ }^{\circ} \mathrm{C}\left(\mathrm{CHCl}_{3}\right) .{ }^{1} \mathrm{H}$ NMR $\left(400 \mathrm{MHz}\right.$, DMSO- $\left.d_{6}\right): \delta 8.61\left(\mathrm{ddd}, J=4.8,1.8,0.9 \mathrm{~Hz}, 4 \mathrm{H}_{\mathrm{a}}\right), 7.82$ (app td, $\left.J=7.7,1.8 \mathrm{~Hz}, 4 \mathrm{H}_{\mathrm{b}}\right), 7.70\left(\mathrm{~s}, 4 \mathrm{H}_{\mathrm{c}}\right), 7.63\left(\mathrm{app} \mathrm{dt}, J=7.8,1.0 \mathrm{~Hz}, 4 \mathrm{H}_{\mathrm{d}}\right), 7.31\left(\mathrm{ddd}, J=7.5,4.8,1.1 \mathrm{~Hz}, 4 \mathrm{H}_{\mathrm{e}}\right)$.

2(1,3-di-I-tFb) $\cdot\left(2,2^{\prime}\right.$-tpcb). Single crystals of $2(1,3-d i-I-t F b) \cdot 2\left(2,2^{\prime}-\mathbf{b p e}\right)$ were ground to a fine powder with an agate mortar and pestle and smeared between two Pyrex plates. The plate assembly was placed in an ACE photocabinet. After $20 \mathrm{~h},{ }^{1} \mathrm{H}$ NMR assay revealed quantitative and stereospecific conversion to $2(\mathbf{1}, \mathbf{3}-\mathbf{d i}-\mathbf{I}-\mathbf{t F b}) \cdot\left(\mathbf{2}, \mathbf{2}^{\prime}\right.$-tpcb). The product powder was scraped from the plates, dissolved in $\mathrm{CHCl}_{3}$ at rt, and allowed to slowly evaporate. Single crystals of 2(1,3-di-I-tFb) $\cdot\left(\mathbf{2}, \mathbf{2}^{\prime}\right.$-tpcb) - colorless plates, suitable for scXRD—formed within $9 \mathrm{~d}$. Analytical data: mp $112-117^{\circ} \mathrm{C}, 154-156{ }^{\circ} \mathrm{C}$ (dec., $\mathrm{CHCl}_{3}$ ) (two distinct melting points were observed: presumably, one for each of the two coformers. Only the second melting point range $\left(154-156^{\circ} \mathrm{C}\right)$ was accompanied by a noticeable decomposition). ${ }^{1} \mathrm{H}$ NMR $\left(400 \mathrm{MHz}\right.$, DMSO- $\left.d_{6}\right): \delta 8.34\left(\mathrm{ddd}, J=4.8,1.8,0.8 \mathrm{~Hz}, 4 \mathrm{H}_{\mathrm{a}}\right), 7.46\left(\operatorname{app} \mathrm{td}, J=7.7,1.8 \mathrm{~Hz}, 4 \mathrm{H}_{\mathrm{b}}\right)$, $7.09\left(\mathrm{~d}, J=7.8 \mathrm{~Hz}, 4 \mathrm{H}_{\mathrm{c}}\right), 6.99\left(\mathrm{ddd}, J=7.4,4.8,1.1 \mathrm{~Hz}, 4 \mathrm{H}_{\mathrm{d}}\right), 4.93\left(\mathrm{~s}, 4 \mathrm{H}_{\mathrm{e}}\right)$.

$(\mathbf{1}, \mathbf{4}-\mathrm{di}-\mathrm{I}-\mathrm{tFb}) \cdot\left(\mathbf{2}, \mathbf{2}^{\prime}\right.$-bpe $)$. Note: $(\mathbf{1}, \mathbf{4}-\mathrm{di}-\mathrm{I}-\mathrm{tFb}) \cdot\left(\mathbf{2}, \mathbf{2}^{\prime}\right.$-bpe $)$ is photosensitive. Cocrystals of $\left(\mathbf{1}, \mathbf{4}\right.$-di-I-tFb) $\cdot\left(\mathbf{2}, \mathbf{2}^{\prime}\right.$-bpe $)$ were obtained by thermal dissolution of $\mathbf{2 , \mathbf { 2 } ^ { \prime }}$-bpe $(92.1 \mathrm{mg}, 0.495 \mathrm{mmol})$ and 1,4-di-I-tFb (208.6 mg, $0.509 \mathrm{mmol}, 1.03$ equiv) in $\mathrm{CHCl}_{3}(2.0 \mathrm{~mL})$. Upon cooling to rt, single crystals of $(\mathbf{1}, \mathbf{4}-\mathrm{di}-\mathrm{I}-\mathrm{tFb}) \cdot\left(\mathbf{2}, \mathbf{2}^{\prime}\right.$-bpe —colorless plates, suitable for scXRD—formed within $24 \mathrm{~h}$. Analytical data: mp 155- $156{ }^{\circ} \mathrm{C}$ (dec., $\left.\mathrm{CHCl}_{3}\right) .{ }^{1} \mathrm{H}$ NMR $\left(400 \mathrm{MHz}, \mathrm{DMSO}-d_{6}\right): \delta 8.61\left(\mathrm{ddd}, J=4.8,1.8,0.9 \mathrm{~Hz}, 4 \mathrm{H}_{\mathrm{a}}\right)$, $7.82\left(\mathrm{app} \mathrm{td}, J=7.7,1.8 \mathrm{~Hz}, 4 \mathrm{H}_{\mathrm{b}}\right), 7.70\left(\mathrm{~s}, 4 \mathrm{H}_{\mathrm{c}}\right), 7.63\left(\mathrm{app} \mathrm{dt}, J=7.8,1.0 \mathrm{~Hz}, 4 \mathrm{H}_{\mathrm{d}}\right), 7.31(\mathrm{ddd}, J=7.5,4.8$, $\left.1.1 \mathrm{~Hz}, 4 \mathrm{H}_{\mathrm{e}}\right)$.

2(1,4-di-I-tFb) $\cdot\left(2,2^{\prime}\right.$-tpcb). Single crystals of $2(1,4-d i-I-t F b) \cdot 2\left(2,2^{\prime}-\right.$ bpe $)$ were ground to a fine powder with an agate mortar and pestle and smeared between two Pyrex plates. The plate assembly was placed in an ACE photocabinet. After $20 \mathrm{~h},{ }^{1} \mathrm{H}$ NMR assay revealed quantitative and stereospecific conversion to 2(1,4-di-I-tFb) $\cdot\left(\mathbf{2}, \mathbf{2}^{\mathbf{\prime}}\right.$-tpcb). Analytical data: ${ }^{\mathbf{1}} \mathbf{H}$ NMR $\left(400 \mathrm{MHz}\right.$, DMSO- $\left.\boldsymbol{d}_{6}\right): \delta 8.34$ (ddd, $\left.J=4.8,1.8,0.8 \mathrm{~Hz}, 4 \mathrm{H}_{\mathrm{a}}\right), 7.46\left(\mathrm{app} \mathrm{td}, J=7.7,1.8 \mathrm{~Hz}, 4 \mathrm{H}_{\mathrm{b}}\right), 7.09\left(\mathrm{~d}, J=7.8 \mathrm{~Hz}, 4 \mathrm{H}_{\mathrm{c}}\right), 6.99(\mathrm{ddd}, J=7.4$, $\left.4.8,1.1 \mathrm{~Hz}, 4 \mathrm{H}_{\mathrm{d}}\right), 4.93\left(\mathrm{~s}, 4 \mathrm{H}_{\mathrm{e}}\right)$.

$(\mathbf{1}, \mathbf{4}-\mathrm{di}-\mathrm{I}-\mathrm{tFb}) \cdot\left(\mathbf{2}, \mathbf{2}^{\prime}\right.$-tpcb). The product powder, $2(\mathbf{1}, \mathbf{4}-\mathrm{di}-\mathrm{I}-\mathrm{tFb}) \cdot\left(\mathbf{2}, \mathbf{2}^{\prime}\right.$-tpcb), was scraped from the plate assembly, dissolved in $\mathrm{CHCl}_{3}$ at $\mathrm{rt}$, and allowed to slowly evaporate. Single crystals of (1,4-di-I-tFb).(2,2'-tpcb) - colorless plates, suitable for scXRD—formed within $6 \mathrm{~d}$. Analytical data: mp $174-175{ }^{\circ} \mathrm{C}$ (dec., $\left.\mathrm{CHCl}_{3}\right)$.

\section{3. ${ }^{1}$ H NMR Spectroscopy}

Proton nuclear magnetic resonance $\left({ }^{1} \mathrm{H}\right.$ NMR) spectra were recorded at room temperature on a Bruker DRX-400 spectrometer at $400 \mathrm{MHz}$ (instrument parameters: field strength: $9.2 \mathrm{~T}$; RF-Console: DRX 3-channel; magnet: shielded superconducting; probe: nature, $5.0 \mathrm{~mm} \mathrm{BBO}-{ }^{1} \mathrm{H} /{ }^{15} \mathrm{~N}-{ }^{31} \mathrm{P}$; type, double-resonance; temperature range, $-100-180^{\circ} \mathrm{C}$ ). ${ }^{1} \mathrm{H}$ NMR data (see Supplementary Materials) are reported as follows: chemical shift $(\delta, \mathrm{ppm})$, multiplicity $(\mathrm{s}=$ singlet, $\mathrm{d}=$ doublet, $\mathrm{ddd}=\mathrm{doublet}$ of doublet of doublets, app $\mathrm{dt}=$ apparent doublet of triplets, app $\mathrm{td}=$ apparent triplet of doublets), coupling constant(s) $(\mathrm{J}, \mathrm{Hz})$, and integration. Chemical shift values were calibrated relative to residual 
solvent resonance (DMSO: $\delta_{\mathrm{H}}=2.50 \mathrm{ppm}$ ) as the internal standard. All NMR data were collected and plotted within the Bruker TopSpin v4.0.6 software suite.

\subsection{Powder X-ray Diffraction ( $p X R D$ )}

Powder X-ray diffraction data were collected at room temperature on a Bruker D8 Advance X-ray diffractometer on samples mounted on glass slides. Each sample was finely ground using an agate mortar and pestle prior to mounting. Instrument parameters: radiation wavelength, $\mathrm{CuK} \alpha$ $\left(\lambda=1.5418 \AA\right.$ ); scan type, coupled TwoTheta/Theta; scan mode, continuous PSD fast; scan range, $5-40^{\circ}$ two-theta; step size, $0.02^{\circ}$; voltage, $40 \mathrm{kV}$; current, $30 \mathrm{~mA}$. Background subtractions were applied to all experimentally collected data within the Bruker DIFFRAC.EVA v3.1 software suite. All data were plotted in Microsoft Excel 2016. Simulated pXRD patterns were calculated from scXRD data within the Cambridge Crystallographic Data Centre (CCDC) Mercury [27] software suite.

\subsection{Single-Crystal X-ray Diffraction (scXRD)}

Single-crystal X-ray diffraction data were collected on either a Bruker Nonius-Kappa APEX II CCD or a Bruker Nonius-Kappa CCD diffractometer, each equipped with an Oxford Cryosystems 700 series cold $\mathrm{N}_{2}$ gas stream cooling system. Data were collected at either room temperature (298.15 K) or low temperature $(150.15 \mathrm{~K})$ using graphite-monochromated MoK $\alpha$ radiation $(\lambda=0.71073 \AA)$. Crystals were mounted in Paratone oil on a MiTeGen magnetic mount. Data collection strategies for ensuring maximum data redundancy and completeness were calculated using the Bruker Apex $\mathrm{II}^{\mathrm{TM}}$ software suite. Data collection, initial indexing, frame integration, Lorentz-polarization corrections, and final cell parameter calculations were likewise accomplished using the Apex II software suite. Multi-scan absorption corrections were performed using SADABS [28]. Structure solution and refinement were accomplished using SHELXT [29] and SHELXL [30], respectively, within the Olex2 [31] graphical user interface. Space groups were unambiguously verified using the PLATON [32] executable. All non-hydrogen atoms were refined anisotropically. All hydrogen atoms were attached via a riding model at calculated positions using suitable HFIX commands. The occupancies of the major and minor positions for the disordered $C=C$ cores within 2(1,3-di-I-tFb) $2\left(\mathbf{2}, \mathbf{2}^{\prime}\right.$-bpe) and $(\mathbf{1}, \mathbf{4}-\mathrm{di}-\mathrm{I}-\mathbf{t F b}) \cdot\left(\mathbf{2}, \mathbf{2}^{\prime}\right.$-bpe) and for the disordered cyclobutane C-C cores within 2(1,3-di-I-tFb) $\cdot\left(\mathbf{2}, \mathbf{2}^{\prime}\right.$-tpcb) and $(\mathbf{1}, \mathbf{4}-\mathbf{d i}-\mathbf{I}-\mathbf{t F b}) \cdot\left(\mathbf{2}, \mathbf{2}^{\prime}\right.$-tpcb) converged to their respective ratios after each was identified in the difference map and freely refined. Figures of all structures were rendered in the CCDC Mercury [27] software suite.

\section{Conclusions}

We demonstrated that X-bonds support intermolecular [2+2] photodimerizations of $\mathbf{2 , 2} \mathbf{2}^{\prime}$-bpe in the solid state. The reaction occurred stereospecifically and quantitatively to generate $\mathbf{2}, \mathbf{2}^{\prime}$-tpcb.

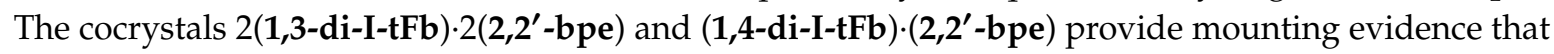
$\mathrm{X}$-bonds can be utilized in a more general way to sustain the formation of $\mathrm{C}$ - $\mathrm{C}$ bonds in solids. Our efforts are now focused on rational approaches to utilize X-bonds to direct stacking and control reactivity in the solid state.

Supplementary Materials: The following are available online, Figure S1: ${ }^{1} \mathrm{H}$ NMR spectrum of 2,2' -bpe, Figure S2: ${ }^{1} \mathrm{H}$ NMR spectrum of 2(1,3-di-I-tFb)·(2,2'-tpcb), Figure S3: ${ }^{1} \mathrm{H}$ NMR spectrum of 2(1,4-di-I-tFb)·(2,2'-tpcb), Figure S4: pXRD pattern of 2(1,3-di-I-tFb)·2(2,2'-bpe), Figure S5: pXRD pattern of 2(1,3-di-I-tFb)·(2, $\mathbf{2}^{\prime}$-tpcb), Figure S6: pXRD pattern of $(\mathbf{1}, \mathbf{4}-\mathbf{d i}-\mathrm{I}-\mathbf{t F b}) \cdot\left(\mathbf{2}, \mathbf{2}^{\prime}\right.$-bpe), Figure S7: pXRD pattern of $\left(\mathbf{1}, \mathbf{4}\right.$-di-I-tFb) $\cdot\left(\mathbf{2}, \mathbf{2}^{\prime}\right.$-tpcb), Tables S1-S4: Crystallographic data and structure refinement statistics for 2(1,3-di-I-tFb) $2\left(\mathbf{2}, \mathbf{2}^{\prime}\right.$-bpe), 2(1,3-di-I-tFb) $\cdot\left(\mathbf{2}, \mathbf{2}^{\prime}\right.$-tpcb), $(\mathbf{1}, \mathbf{4}-\mathrm{di}-\mathrm{I}-\mathrm{tFb}) \cdot\left(\mathbf{2}, \mathbf{2}^{\prime}\right.$-bpe $)$, and $(\mathbf{1}, \mathbf{4}-\mathrm{di}-\mathrm{I}-\mathbf{t F b}) \cdot\left(\mathbf{2}, \mathbf{2}^{\prime}\right.$-tpcb), Table S5: Bond metrics for cocrystals, Table S6: Melting point data for cocrystals and coformers thereof.

Author Contributions: Conceptualization, J.Q. and L.R.M.; methodology, J.Q.; formal analysis, J.Q., D.C.S., and L.R.M.; investigation, J.Q. and L.R.M.; resources, L.R.M.; writing—original draft preparation, J.Q. and L.R.M.; writing-review and editing, J.Q. and L.R.M.; supervision, L.R.M.; funding acquisition, L.R.M. All authors have read and agreed to the published version of the manuscript. 
Funding: This research was funded by the National Science Foundation, grant number LRM DMR-1708673.

Conflicts of Interest: The authors declare no conflict of interest. The funders had no role in the design of the study; in the collection, analyses, or interpretation of data; in the writing of the manuscript, or in the decision to publish the results.

\section{References}

1. Cavallo, G.; Metrangolo, P.; Milani, R.; Pilati, T.; Priimagi, A.; Resnati, G.; Terraneo, G. The Halogen Bond. Chem. Rev. 2016, 116, 2478-2601. [CrossRef] [PubMed]

2. Allen, F.H.; Goud, B.S.; Hoy, V.J.; Howard, J.A.K.; Desiraju, G.R. Molecular Recognition via Iodo·Nitro and Iodo-Cyano Interactions: Crystal Structures of the 1:1 Complexes of 1, 4-Diiodobenzene with 1, 4-Dinitrobenzene and 7, 7, 8, 8-Tetracyanoquinodimethane (TCNQ). J. Chem. Soc. Chem. Commun. 1994, 23, 2729-2730. [CrossRef]

3. Reddy, D.S.; Craig, D.C.; Rae, A.D.; Desiraju, G.R. N..Br Mediated Diamondoid Network in the Crystalline Complex Carbon Tetrabromide: Hexamethylenetetramine. J. Chem. Soc. Chem. Commun. 1993, 23, 1737-1739. [CrossRef]

4. Desiraju, G.R.; Ho, P.S.; Kloo, L.; Legon, A.C.; Marquardt, R.; Metrangolo, P.; Politzer, P.; Resnati, G.; Rissanen, K. Definition of the Halogen Bond (IUPAC recommendations 2013). Pure Appl. Chem. 2013, 85, 1711-1713. [CrossRef]

5. Marras, G.; Metrangolo, P.; Meyer, F.; Pilati, T.; Resnati, G.; Vij, A. Solid State Synthesis Under Supramolecular Control of a 2D Heterotetratopic Self-Complementary Tecton Tailored to Halogen Bonding. New J. Chem. 2006, 30, 1397-1402. [CrossRef]

6. Sun, A.; Lauher, J.W.; Goroff, N.S. Preparation of Poly(diiododiacetylene), an Ordered Conjugated Polymer of Carbon and Iodine. Science 2006, 312, 1030-1034. [CrossRef]

7. Sinnwell, M.A.; MacGillivray, L.R. Halogen-Bond-Templated [2+2] Photodimerization in the Solid State: Directed Synthesis and Rare Self-Inclusion of a Halogenated Product. Angew. Chem. Int. Ed. 2016, 55, 3477-3480. [CrossRef] [PubMed]

8. Caronna, T.; Liantonio, R.; Logothetis, T.A.; Metrangolo, P.; Pilati, T.; Resnati, G. Halogen Bonding and $\pi \cdots \pi$ Stacking Control Reactivity in the Solid State. J. Am. Chem. Soc. 2004, 126, 4500-4501. [CrossRef]

9. Guido, E.; Metrangolo, P.; Panzeri, W.; Pilati, T.; Resnati, G.; Ursini, M.; Logothetis, T.A. Pentaerythritol tetrakis(4-iodo-2,3,5,6-tetrafluorophenyl) ether: A Tecton for the Self-Assembly of Double Strand 1D Infinite Chains. J. Fluorine Chem. 2005, 126, 197-207. [CrossRef]

10. Walsh, R.B.; Padgett, C.W.; Metrangolo, P.; Resnati, G.; Hanks, T.W.; Pennington, W.T. Crystal Engineering through Halogen Bonding: Complexes of Nitrogen Heterocycles with Organic Iodides. Cryst. Growth Des. 2001, 1, 165-175. [CrossRef]

11. Quentin, J.; MacGillivray, L.R. Halogen- versus Hydrogen-Bonding in Binary Cocrystals: Novel Conformation a Coformer with [2+2] Photoreactivity of Criss-Crossed C=C Bonds. Chem. Phys. Chem. 2019, 21, 154-163. [CrossRef]

12. Görbitz, C.H. The Development and Use of a Crystallographic Database. Acta Cryst. 2016, B72, 171-179. [CrossRef]

13. Peedikakkal, A.M.P.; Vittal, J.J. Solid-State Photochemical [2+2] Cycloaddition in a Hydrogen-Bonded Metal Complex Containing Several Parallel and Crisscross C=C Bonds. Chem. Eur. J. 2008, 14, 5329-5334. [CrossRef]

14. Harada, J.; Ogawa, K. Topics in Stereochemistry, Vol. 25; Denmark, S.E., Siegel, J.S., Eds.; Wiley: Chichester, UK, 2006; pp. 31-47.

15. Harada, J.; Ogawa, K. Invisible but Common Motion in Organic Crystals: A Pedal Motion in Stilbenes and Azobenzenes. J. Am. Chem. Soc. 2001, 123, 10884-10888. [CrossRef]

16. Harada, J.; Ogawa, K.; Tomoda, S. The Central Bond Length in 1, 2- Diphenylethanes. J. Am. Chem. Soc. 1995, 117, 4476-4478. [CrossRef]

17. Ogawa, K.; Sano, T.; Yoshimura, S.; Takeuchi, Y.; Toriumi, K. Molecular Structure and Intramolecular Motion of $(E)$-Stilbenes in Crystals. An Interpretation of the Unusually Short Ethylene Bond. J. Am. Chem. Soc. 1992, 114, 1041-1051. [CrossRef] 
18. Harada, J.; Ogawa, K.; Tamoda, S. Molecular Motion and Conformational Interconversion of Azobenzenes in Crystals as Studied by X-ray Diffraction. Acta Cryst. 1997, B53, 662-672. [CrossRef]

19. Harada, J.; Ogawa, K. Ethane Bond Length in 1, 2-Ddiphenylethanes. Struct. Chem. 2001, 12, $243-250$. [CrossRef]

20. Harada, J.; Ogawa, K. X- ray Diffraction Analysis of Nonequilibrium States in Crystals: Observation of an Unstable Conformer in Flash- Cooled Crystals. J. Am. Chem. Soc. 2004, 126, 3539-3544. [CrossRef]

21. Harada, J.; Harakawa, M.; Ogawa, K. Conformational Change of N-Bbenzylideneanilines in Crystals. Acta Cryst. 2004, B60, 589-597. [CrossRef]

22. Ohba, S.; Hosomi, H.; Ito, Y. In Situ X-ray Observation of Pedal- like Conformational Change and Dimerization of trans- Cinnamamide in Cocrystals with Phthalic Acid. J. Am. Chem. Soc. 2001, 123, 6349-6352. [CrossRef] [PubMed]

23. Ben-Efraim, D.A.; Green, B.S. Use of Mid- Points or Average NMR Chemical Shifts in Stereochemical Assignments. Tetrahedron 1974, 30, 2357-2364. [CrossRef]

24. Vansant, J.; Toppet, S.; Smets, G. Azastilbenes. 2. Photodimerization. J. Org. Chem. 1980, 45, $1565-1573$. [CrossRef]

25. Venkataraman, D.; Lee, S.; Moore, J.S.; Zhang, P.; Hirsch, K.A.; Gardner, G.B.; Covey, A.C.; Prentice, C.L. Coordination Networks Based on Multitopic Ligands and Silver(I) Salts: A Study of Network Connectivity and Topology as a Function of Counterion. Chem. Mater. 1996, 8, 2030-2040. [CrossRef]

26. Lu, W.; Wei, Z.; Gu, Z.-Y.; Liu, T.-F.; Park, J.; Park, J.; Tian, J.; Zhang, M.; Zhang, Q.; Gentle, T., III; et al. Tuning the Structure and Function of Metal-Organic Frameworks via Linker Design. Chem. Soc. Rev. 2014, 43, 5561-5593. [CrossRef]

27. Macrae, C.F.; Bruno, I.J.; Chisholm, J.A.; Edgington, P.R.; McCabe, P.; Pidcock, E.; Rodriguez-Monge, L.; Taylor, R.; van de Streek, J.; Wood, P.A. Mercury CSD 2.0-New Features for the Visualization and Investigation of Crystal Structures. J. Appl. Cryst. 2008, 41, 466-470. [CrossRef]

28. Otwinowski, Z.; Minor, W. Processing of X-Ray Diffraction Data Collected in Oscillation Mode. Methods Enzymol. 1997, 276, 307-326. [CrossRef]

29. Sheldrick, G.M. SHELXT-Integrated Space-Group and Crystal-Structure Determination. Acta Cryst. 2015, A71, 3-8. [CrossRef]

30. Sheldrick, G.M. Crystal Structure Refinement with SHELXL. Acta Cryst. 2015, C71, 3-8. [CrossRef]

31. Dolomanov, O.V.; Bourhis, L.J.; Gildea, R.J.; Howard, J.A.K.; Puschmann, H. OLEX2: A Complete Structure Solution, Refinement and Analysis Program. J. Appl. Cryst. 2009, 42, 339-341. [CrossRef]

32. Spek, A.L. Structure Validation in Chemical Crystallography. Acta Cryst. 2009, D65, 148-155. [CrossRef]

Sample Availability: Samples of the compounds 2(1,3-di-I-tFb)·2(2,2'-bpe), (1,4-di-I-tFb)·(2,2'-bpe), $2(\mathbf{1}, \mathbf{3}-$ di-I-tFb) $\cdot\left(2,2^{\prime}-\mathbf{t p c b}\right)$, and $(1,4-d i-I-t F b) \cdot\left(2,2^{\prime}-\mathbf{t p c b}\right)$ are available from the authors. 